\title{
Early and midterm outcomes of quick proximal arch replacement with mild hypothermia and rapid rewarming for type A acute aortic dissection
}

\author{
Mitsumasa Hata, MD, PhD, Kenji Akiyama, MD, Hiroaki Hata, MD, Akira Sezai, MD, \\ Isamu Yoshitake, MD, Shinji Wakui, MD, and Motomi Shiono, MD
}

Objective: We assessed the efficacy of our unique procedure with mild hypothermic circulatory arrest and rapid rewarming during emergency surgery for type A acute aortic dissection.

\begin{abstract}
Methods: During the last 6 years, 91 patients with acute aortic dissection and an average age of $66.2 \pm 14.1$ years underwent our newly modified quick hemiarch replacement. Eighteen patients $(19.8 \%)$ had independent predictors for surgical mortality, such as preoperative cardiopulmonary arrest or malperfusion of vital organs. During open distal anastomosis with a rectal temperature of $28^{\circ} \mathrm{C}$ without any cerebral perfusion, circulating blood in the cardiopulmonary bypass circuit was warmed to $40^{\circ} \mathrm{C}$, accompanied by warming of the patient's body using a heating mat. As soon as distal anastomosis was completed, rapid rewarming was initiated by $40^{\circ} \mathrm{C}$ blood perfusion.

Results: Circulatory arrest, cardiopulmonary bypass, and overall operation times were $19.1 \pm 5.1,86.2 \pm 17.8$, and $150.1 \pm 25.2$ minutes, respectively. Five patients $(5.5 \%)$ required reexploration for bleeding, and 4 patients $(4.4 \%)$ had strokes, but none had acute renal failure. The hospital mortality rate was $3.3 \%$ ( 3 patients), and the postoperative hospital stay was $10.6 \pm 4.7$ days. Five patients required replacement of the distal arch or descending aorta at a later stage. Eight patients died during follow-up. A postoperative midterm computed tomography scan revealed a closed distal arch in more than $80 \%$ of patients and partial abdominal open false lumen in $45 \%$ of patients. Echocardiograms showed mild aortic valve regurgitation in 8 patients. The freedom from reoperation rate at 5 years was $90.0 \%$. Actuarial survival including operative death was $82.7 \%$ at 5 years.
\end{abstract}

Conclusions: Our original technique is a safe and less-invasive procedure that enables a quicker surgery. The midterm outcome also was favorable. (J Thorac Cardiovasc Surg 2013;146:119-23)

Although recent emergency surgical outcome for type A acute aortic dissection (AAD) has been improving, ${ }^{1-3}$ the Japanese Thoracic and Cardiovascular Society has reported that the surgical mortality rate is still estimated to be approximately $10.5 \%$, even in ascending or proximal hemiarch replacement. ${ }^{4}$ This high mortality rate is associated with various complications, such as uncontrollable bleeding, renal and respiratory failure, brain damage, infection, or becoming bedridden because of the extensive surgical stress caused by deep hypothermia and longer durations of cardiopulmonary bypass (CPB) and overall surgery. ${ }^{5,6}$ Therefore, if surgical stress can be minimized by shortening the duration of brain ischemic stress, $\mathrm{CPB}$, and

\footnotetext{
From the Department of Cardiovascular Surgery, Nihon University School of Medicine, Tokyo, Japan.

Disclosures: Authors have nothing to disclose with regard to commercial support. Received for publication April 5, 2012; revisions received June 7, 2012; accepted for publication June 18, 2012; available ahead of print July 23, 2012.

Address for reprints: Mitsumasa Hata, MD, PhD, the Department of Cardiovascular Surgery, Nihon University School of Medicine, 30-1 Oyaguchi Kamimachi Itabashi-ku, Tokyo 173-8610, Japan (E-mail: hata.mitsumasa@nihon-u.ac.jp). $0022-5223 / \$ 36.00$

Copyright (C) 2013 by The American Association for Thoracic Surgery http://dx.doi.org/10.1016/j.jtcvs.2012.06.047
}

operative procedures, the surgical outcome for AAD could be further improved.

In most patients with $\mathrm{AAD}$, proximal arch replacement is sufficient because the intimal tear is located in the concavity of the transverse arch. ${ }^{7}$ Kamiya and colleagues ${ }^{8}$ recently reported that moderate hypothermic arrest at $26^{\circ} \mathrm{C}$ to $28^{\circ} \mathrm{C}$ without any adjunctive cerebral protection is safe during hemiarch aortic replacement. In view of these factors, we established a new procedure for proximal arch replacement using mild hypothermic circulatory arrest without cerebral perfusion, followed by aggressive rapid rewarming to shorten the duration of brain ischemia, CPB, and overall surgery. We have reported the initial results of this procedure for octogenarians with $\mathrm{AAD}^{9}$ and performed the procedure as much as possible in patients undergoing emergency proximal arch replacement for AAD. The current study assessed the early and midterm outcomes of our unique technique.

\section{PATIENTS AND METHODS}

Between December 2005 and December 2011, 164 patients with AAD underwent emergency surgery at the Nihon University School of Medicine. Among them, 93 consecutive patients underwent emergency proximal arch replacement with this original technique conducted by 1 surgeon (M.H.) or other surgeons under the supervision of the primary author. However, 


\section{Abbreviations and Acronyms \\ $\mathrm{AAA}=$ acute aortic dissection \\ $\mathrm{AR}=$ aortic regurgitation \\ $\mathrm{CPB}=$ cardiopulmonary bypass \\ $\mathrm{CT}=$ computed tomography \\ DHA $=$ deep hypothermic arrest \\ $\mathrm{GRF}=$ gelatin resorcin formalin \\ $\mathrm{POD}=$ postoperative day}

2 patients were excluded because of conversion to entire arch replacement using cerebral perfusion during surgery. Accordingly, 91 patients were reviewed. Institutional review board approval was provided before publication of this article and reporting of the information. Forty-eight patients $(52.7 \%)$ were male, and the average age was $66.2 \pm 14.1$ years (range, $35-88$ years). Contrast computed tomography (CT) was performed in all patients as soon as they were referred to the hospital. Transthoracic echocardiography was then performed to detect pericardial effusion and assess aortic regurgitation (AR) and cardiac function. The contrast $\mathrm{CT}$ revealed a thrombosed occlusion-type condition in 50 patients $(54.9 \%)$. Table 1 shows the preoperative patient comorbidity. Thirty-one patients $(34.1 \%)$ were in a preshock state due to cardiac tamponade. Eleven patients $(12.1 \%)$ had moderate AR, and the condition of 7 patients $(7.7 \%)$ was complicated by acute myocardial infarction. Vital organ malperfusion occurred in 16 patients: unconsciousness in $9(9.9 \%)$, colitis in $5(5.5 \%)$, arm ischemia in $1(1.1 \%)$, and paraplegia in $1(1.1 \%)$ (Table 1$)$. Ten patients $(11.0 \%)$ required intubation before arriving at the hospital, and 4 patients $(5.5 \%)$ underwent cardiopulmonary resuscitation administered with an electrodefibrillator before entering the operating room (Table 1). These symptoms were frequently overlapped in many patients, resulting in $18 \mathrm{pa}-$ tients $(19.8 \%)$ having predictors for surgical mortality, such as vital organ malperfusion or preoperative cardiopulmonary arrest. ${ }^{6}$

\section{Surgical Procedure}

CPB was implemented via femoral arterial cannulation. The ascending aorta was clamped and opened longitudinally. St Thomas cardioplegia was selectively administered to both coronary arteries. During cooling, the aortic segment containing the intimal tear was resected and gelatin resorcin formalin (GRF) glue was applied between the 2 dissected walls on the proximal stumps of the aorta, and the aortic walls were reinforced by securing Teflon felt strips inside and outside the aorta. We used the glue as little as possible and mixed approximately 1 part formalin to 10 parts gelatin. Circulatory arrest was then implemented at a rectal temperature of $28^{\circ} \mathrm{C}$ with no cerebral perfusion. The stump of the proximal arch was fixed in the same way. During open distal anastomosis, circulating blood in the CPB circuit was warmed to $40^{\circ} \mathrm{C}$ by the maximum level of heat exchanger, and the patient's body (except for the head) was also warmed using the Medi-Term II hyper-hypothermia system (GAYMAR Inc, Orchard Park, NY). As soon as distal anastomosis was completed, antegrade systemic circulation was established through a side branch of the polyester prosthesis (Triplex; Terumo Corp, Tokyo, Japan), and rapid rewarming was initiated by $40^{\circ} \mathrm{C}$ blood perfusion. As soon as the patient's blood was mixed by a shot of $40^{\circ} \mathrm{C}$ blood, drainage blood temperature increased to $30^{\circ} \mathrm{C}$ and arterial blood temperature decreased to $34^{\circ} \mathrm{C}$. Therefore, the temperature balance between infusion and drainage blood was kept at less than $5^{\circ} \mathrm{C}$ during rapid rewarming. The head ice pack was taken away during rapid rewarming. Tear-oriented replacement of the aortic segment containing the intimal tear was used as much as possible. However, if the intimal tear was located in the distal arch to the descending aorta, only the ascending aorta was replaced. All patients were medically treated with a calcium antagonist or beta-blocker after surgery.
The mean duration of follow-up was 39.7 \pm 21.2 months (range, 3-75 months). Follow-up information was obtained for all patients. At the time of the study, we evaluated the presence of postoperative AR and the patency of the distal false lumen using echocardiography and contrast CT scans. The freedom from reoperation and actuarial survival were calculated using the Kaplan-Meier method.

\section{RESULTS}

Intimal tear was resected in 79 patients $(86.8 \%)$. Coronary bypass surgery was concomitantly performed in 5 patients because the intimal tear was located on the coronary orifice. Aortic valve replacement was required in 4 patients with severe AR caused by a huge false lumen on the sinus of Valsalva. No patients had an intimal tear around the aortic root. The average minimum rectal temperature was $27.3^{\circ} \mathrm{C} \pm 1.1^{\circ} \mathrm{C}$. The durations of circulatory arrest, $\mathrm{CPB}$, and total surgical procedure were $19.1 \pm 5.1$ minutes (range, 10-25), $86.2 \pm 17.8$ minutes, and $150.1 \pm 25.2 \mathrm{~min}-$ utes, respectively (Table 2). The durations of postoperative mechanical ventilation and hospital stay were $13.0 \pm 12.2$ hours and $10.6 \pm 4.7$ days, respectively (Table 2 ). Five patients $(5.5 \%)$ were taken back to the operating room for bleeding (Table 3 ). Four patients $(4.4 \%)$ had temporal neurologic dysfunction, such as mild intellectual disturbance, confusion, disorientation, or memory disturbance (Table 3 ). Postoperative permanent brain damage occurred in 4 patients $(4.4 \%)$, pneumonia occurred in 2 patients $(2.2 \%)$, and tracheostomy occurred in 3 patients (3.3\%) (Table 3). However, no patients had postoperative renal failure or paraplegia. The hospital mortality rate was 3.3\% (3 patients): One patient died of stroke on postoperative day (POD) 11, 1 patient died of redissection on POD 2, and 1 patient died of malperfusion of the lower body on POD 2. Five patients required reoperation at a later stage. Distal arch to descending aortic replacement was performed in 2 patients, aortic root replacement was performed in 2 patients, and entire arch replacement was performed in $1 \mathrm{pa}-$ tient. Eight patients died during follow-up (Table 4). Contrast CT scans were conducted in 62 patients at a later stage, revealing occlusion of the distal arch to the descending false lumen in 51 patients $(82.3 \%)$ and partial patent false lumen of the abdominal aorta in 28 patients $(45.2 \%)$. Echocardiograms at a later stage showed mild AR in 8 patients $(11.4 \%)$ and moderate to severe AR in 2 patients who underwent aortic root replacement. The freedom from reoperation rate (Figure 1) and actuarial survival including hospital death (Figure 2) at 5 years were $90.0 \%$ and $82.7 \%$, respectively.

\section{DISCUSSION}

Considering the aging patient populations in western and Asian societies with prolonged survival despite hypertension and the excellent diagnostic modalities available to more patients, cardiovascular centers face an increasing 
TABLE 1. Preoperative morbidity

\begin{tabular}{lc}
\hline Cardiac tamponade & $31(34.1 \%)$ \\
AR & $11(12.1 \%)$ \\
Acute myocardial infarction & $7(7.7 \%)$ \\
Unconsciousness & $9(9.9 \%)$ \\
Ischemic colitis & $5(5.5 \%)$ \\
Arm ischemia & $1(1.1 \%)$ \\
Paraplegia & $1(1.1 \%)$ \\
Intubation before arrival & $10(11.0 \%)$ \\
Cardiopulmonary arrest & $5(5.5 \%)$ \\
\hline
\end{tabular}

$A R$, Aortic regurgitation.

incidence of AAD. In particular, the incidence of AAD in Japan is approximately 9000 cases per year. Approximately 30 patients with AAD are transferred to the Nihon University School of Medicine in 1 year. Therefore, recent advances in surgical techniques, anesthesia, and perioperative medical management are likely to have decreased the mortality of individuals undergoing emergency operations for AAD during the last few years. On the other hand, the complexity of patients undergoing this procedure, in terms of age, comorbidities, and concomitant procedures, is increasing and may negate the impact of the beneficial advances. Recent data show preoperative hypotension, shock, and cardiac tamponade to be independent predictors of operative mortality for AAD. ${ }^{10,11}$ In particular, if cardiopulmonary resuscitation is required for pulseless shock and respiratory distress, malperfusion in the vital organs may have already developed during the resuscitation. Bayegan and colleagues ${ }^{12}$ reported that preoperative severe cardiac tamponade without palpable pulses were associated with preoperative death. Therefore, patients who have already reached such a critical level by the time of presentation to the hospital may not be able to tolerate the additional surgical stress of deep hypothermia, a long duration of cerebral exclusion, or CPB. ${ }^{13}$ Furthermore, a prolonged operation can increase mortality through coagulopathy, cerebral ischemia, infection, or multiple organ failure for patients who are already in critical condition. ${ }^{14}$ Therefore, particularly for such high-risk patients, performing surgery with minimum invasive stress is considered to be a key factor for saving lives.

Kamiya and colleagues ${ }^{8}$ reported a quick proximal arch replacement in which distal anastomosis was performed using mild hypothermia $\left(26^{\circ} \mathrm{C}-28^{\circ} \mathrm{C}\right)$ with no cerebral

\section{TABLE 2. Operative characteristics}

\begin{tabular}{lc}
\hline Rectal temperature $\left({ }^{\circ} \mathrm{C}\right)$ & $27.3 \pm 1.1$ \\
Circulatory arrest $(\mathrm{min})$ & $19.1 \pm 5.1$ \\
$\mathrm{CPB}(\mathrm{min})$ & $86.2 \pm 17.8$ \\
Total surgery (min) & $150.1 \pm 25.2$ \\
Mechanical ventilation (h) & $13.1 \pm 12.2$ \\
Hospital stay (d) & $10.6 \pm 4.7$ \\
\hline
\end{tabular}

$C P B$, Cardiopulmonary bypass.
TABLE 3. Complications

\begin{tabular}{ll}
\hline Temporally neurologic dysfunction & $4(4.4 \%)$ \\
Reexploration & $5(5.5 \%)$ \\
Brain damage & $4(4.4 \%)$ \\
Pneumonia & $2(2.2 \%)$ \\
Tracheostomy & $3(3.3 \%)$ \\
Mortality & $3(3.3 \%)$ \\
\hline
\end{tabular}

perfusion. They reported that distal anastomosis can be completed in approximately 8 minutes. This is because almost all of their patients had a true aneurysm, in which aortic stump fixation using GRF glue or Teflon felt is not required. However, the durations of CPB and overall operation for their procedures were approximately 130 and 240 minutes, respectively, ${ }^{8}$ which were longer than those of our original procedure. In this unique technique conducted thus far, although it took approximately 19 minutes to complete the distal anastomosis because of the requirement of aortic stump fixation with GRF glue and Teflon felt, the durations for CPB and the overall operation were approximately 80 and 150 minutes, respectively. This is because the key factor in our original procedure is rapid rewarming. It has been generally accepted that rewarming from hypothermia should be conducted as slowly as possible. ${ }^{15}$ In the deep hypothermic arrest (DHA) technique, cerebral metabolism and oxygen extraction remain significantly reduced during rewarming and after $\mathrm{CPB}$, suggesting disordered cerebral metabolism and oxygen use after DHA. Furthermore, cerebral blood flow significantly decreases in patients with DHA during the rewarming phase. ${ }^{16}$ If cerebral circulation is unable to regulate oxygen delivery after DHA, the brain becomes at an increased risk of hypoxic injury during episodes of hypoxemia in the rewarming phase. ${ }^{17}$ Therefore, we speculate that the potential mismatches in flow/metabolism after DHA are most likely expressed during rapid temperature or perfusion changes, such as during rewarming. On the other hand, Greeley and colleagues ${ }^{18}$ reported that patients cooled to $28^{\circ} \mathrm{C}$ demonstrated a return to baseline in cerebral blood flow during rewarming and after weaning from CPB. Therefore, there is no problem with inducing rapid rewarming after circulatory arrest with mild hypothermia $\left(28^{\circ} \mathrm{C}\right)$. Moreover, rapid rewarming can shorten the durations of $\mathrm{CPB}$ and the overall operation. In general, quicker is not always better. Particularly in high-risk patients with predictors of mortality, quicker surgery results in a better

\section{TABLE 4. Late death}

\begin{tabular}{ll}
\hline Acute myocardial infarction & 3 patients \\
Stroke & 1 patient \\
Cerebral hemorrhage & 1 patient \\
Pneumonia & 1 patient \\
Traffic accident & 1 patient \\
Sepsis (during hemodialysis) & 1 patient \\
\hline
\end{tabular}




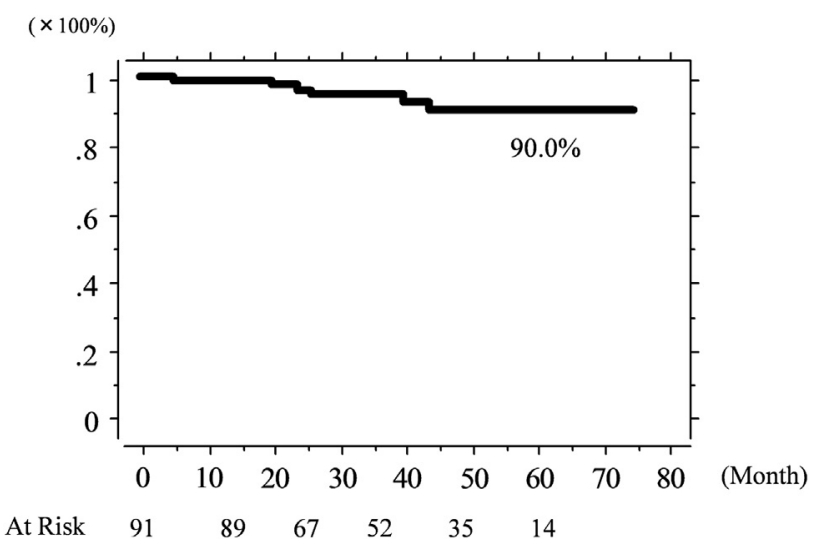

FIGURE 1. Freedom from reoperation rate at 5 years was $90.0 \%$.

outcome because the surgical stress due to hypothermia or $\mathrm{CPB}$ minimum is minimized for patients who are already in a critical state. In the present study, our procedure led to the prevention of severe complications and a surgical mortality rate of just $3.3 \%$, regardless of approximately $20 \%$ of the patients having predictors for surgical mortality.

The first priority of this unique procedure is primary tear excision and the avoidance of serious complications. In the majority of patients, an ascending or proximal arch replacement is sufficient because the intimal tear is generally located in the concavity of the transverse arch. ${ }^{19}$ In the present study, an intimal tear was resected in more than $85 \%$ of the patients. Kazui and colleagues ${ }^{20}$ and Hirotani and colleagues ${ }^{21}$ advocate systematic extended or total aortic arch resection for the initial surgical management of $\mathrm{AAD}$, irrespective of the location of the intimal tear. Although their studies provided satisfactory results, we have to keep in mind that AAD is an inherently lethal condition. If the patient survives the acute episode, this constitutes a success, regardless of the later onset of further aortic problems. Such an extended approach will necessarily increase an already high operative risk. Ehrlich and colleagues ${ }^{7}$ reported that the site of the intimal tear does not influence

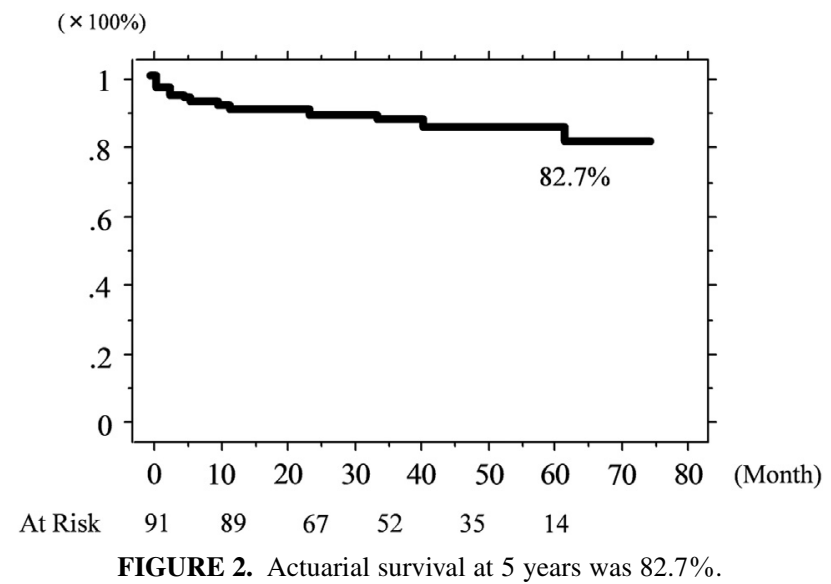

the outcome and that the mortality rate is higher with more extensive resection. Kazui and colleagues ${ }^{20}$ reported that the early mortality rate of emergency total arch replacement was $16 \%$, and the freedom from reoperation was $77 \%$ at 5 years. ${ }^{20}$ Even though emergency intervention for primary tear excision was performed, our original procedure showed that the freedom from reoperation was $90.0 \%$ at 5 years. This may be related to careful postoperative management with antihypertension medications and CT follow-up by cardiovascular surgeons and cardiologists. Extended surgery largely outweighs the relatively low incidence of reoperation and the associated operative risk.

In the present study, approximately $20 \%$ of the patients had predictors for early mortality. For such patients, we have to open the chest as soon as possible to release the tamponade and sometimes set up the CPB during direct cardiac massage. Therefore, at Nihon University School of Medicine, all patients underwent femoral cannulation because it was considered to be quicker and safer. In this series, no patient had malperfusion by femoral access. However, it should be switched to antegrade blood perfusion with a side-arm to ensure blood perfusion in the true lumen after excision of the intimal tear. ${ }^{3}$ Therefore, we used a side-arm for blood perfusion after the open distal anastomosis in all patients.

Mild to moderate AR is well tolerated. Many patients are left with mild to moderate AR after AAD repair and do well for many years. Proximal aortic stamp fixation with the aid of biologic glue enabled us to preserve the native aortic valve whenever possible. The quality of aortic wall adhesion by GRF glue may explain the absence of late AR in most patients because the deformation of the aortic annulus could be repaired and the commissure support system could be restored by adhesion of the dissected layers. In this series, 11 patients $(12.1 \%)$ had AR rated more than grade II, and we replaced the aortic valve in only 4 patients with severe AR. At the time of this study, AR was not rated higher than grade II for the other patients. This represents a successful outcome, even if further attention is required in the future. Postoperative patency and dilatation of the false lumen are also important, as emphasized recently in several reports. ${ }^{22,23}$ In the present study, even though emergency intervention for primary tear excision was performed, only 5 patients have returned to the hospital for secondary operations. Furthermore, the false lumen on the distal aortic arch was closed with thrombus in more than $80 \%$ of the patients in our study. As mentioned earlier, this is favorable compared with previous reports. David and colleagues ${ }^{24}$ reported that the prevalence of a postoperative patent false lumen was reduced from $91 \%$ to $59 \%$ when using the open distal anastomosis technique. During an emergency initial operation for AAD, open repair and fixation of the distal aortic stump with GRF glue decrease the false lumen patency rate and may improve prolonged survival. ${ }^{3}$ 


\section{CONCLUSIONS}

Our newly modified quick proximal arch replacement with moderate hypothermic circulatory arrest followed by aggressive, rapid rewarming is safe, reduces the time required for surgery significantly, and provides a lessinvasive procedure. Our recent emergency surgical aortic repair using this unique technique for $\mathrm{AAD}$ has demonstrated a satisfactory midterm survival.

\section{References}

1. Shiono M, Hata M, Sezai A, Nino T, Yagi S, Negishi N. Validity of a limited ascending and hemiarch replacement for acute type A aortic dissection. Ann Thorac Surg. 2006;82:1665-9.

2. Tanaka M, Kimura N, Yamaguchi A, Adachi A. In-hospital and long-term results of surgery for acute type A aortic dissection: 243 consecutive patients. Ann Thorac Cardiovasc Surg. 2012;18:18-23.

3. Hata M, Shiono M, Sezai A, Iida M, Negishi N, Sezai Y. Type A acute aortic dissection: immediate and mid-term results of emergency aortic replacement with the aid of gelatin resorcin formalin glue. Ann Thorac Surg. 2004;78: 853-7.

4. Sakata R, Fujii Y, Kuwano H. Thoracic and cardiovascular surgery in Japan during 2009. Gen Thorac Cardiovasc Surg. 2011;59:636-67.

5. Hata M, Sezai A, Niino T, Yoda M, Unosawa S, Minami K, et al. Should emergency surgical intervention be performed for octogenarian with type A acute aortic dissection? J Thorac Cardiovasc Surg. 2008;135:1042-6.

6. Hata M, Sezai A, Yoshitake I, Wakui S, Minami K, Shiono M, et al. Clinical trends in optimal treatment strategy for type A acute aortic dissection. Ann Thorac Cardiovasc Surg. 2010;16:228-35.

7. Ehrlich MP, Ergin MA, McCullough JN, Lansman SL, Galla JD, Griepp RB, et al. Results of immediate surgical treatment of all acute type A dissections. Circulation. 2000;102(Suppl 3):248-52.

8. Kamiya H, Hagl C, Kropivnitskaya I, Weidermann J, Kallenbach K, Haverich A, et al. Quick proximal arch replacement with moderate hypothermic circulatory arrest. Ann Thorac Surg. 2007;83:1055-8.

9. Hata M, Suzuki M, Sezai A, Niino T, Yoshitake I, Minami K, et al. Less Invasive Quick Replacement (LIQR) for octogenarians with type A acute aortic dissection. J Thorac Cardiovasc Surg. 2008;136:489-93.
10. Hagan PG, Nienaber CA, Isselbacher EM, Bruckman D, Karavite DJ, Russman PL, et al. The International Registry of Acute Aortic Dissection (IRAD); new insights into an old disease. JAMA. 2000;283:897-903.

11. Mehta RH, Suzuki T, Hagan PG, Bossone E, Gilon D, Llovet A, et al. Predicting death in patients with acute type A aortic dissection. Circulation. 2002;105:200-6.

12. Bayegan K, Domanovits H, Schillinger M, Ehrlich M, Sodeck G, Laggner AN Acute type A aortic dissection: the prognostic impact of preoperative cardiac tamponade. Eur J Cardiothorac Surg. 2001;20:1194-8.

13. Westaby S, Saito S, Katsumata T. Acute type A dissection: conservative methods provide consistently low mortality. Ann Thorac Surg. 2002;73:707-13.

14. Bachet J, Goudot B, Dreyfus GD, Brodaty D, Dubois C, Delentdecker P, et al Surgery for acute type A aortic dissection: The Hospital Foch experience (1977-1998). Ann Thorac Surg. 1999;67:2006-9.

15. Rosner MJ, Rosner SD, Johnson AH. Cerebral perfusion pressure: managemen protocol and clinical results. J Neurosurg. 1995;83:949-62.

16. Croughwell ND, Frasco P, Blumenthal JA, Leone BJ, White WD, Reves JG Warming during cardiopulmonary bypass is associated with jugular bulb desaturation. Ann Thorac Surg. 1992;53:827-32.

17. Tsui SSL, Schultz JM, Shen I, Ungerleider RM. Postoperative hypoxemia exacerbates potential brain injury after deep hypothermic circulatory arrest. Ann Thorac Surg. 2003;78:188-96.

18. Greeley WJ, Kern FH, Ungerleider RM, Boyd JL III, Quill T, Smith LR, et al. The effect of hypothermic cardiopulmonary bypass and total circulatory arrest on cerebral metabolism in neonates, infants, and children. J Thorac Cardiovasc Surg. 1991;101:783-94.

19. Bachet JE. Acute type A aortic dissection: can we dramatically reduce the surgical mortality? Ann Thorac Surg. 2002;73:701-3.

20. Kazui T, Washiyama N, Muhammad BA, Terada H, Yamashita K, Takinami M, et al. Extended total arch replacement for acute type A aortic dissection: experience with seventy patients. $J$ Thorac Cardiovasc Surg. 2000;119:558-65.

21. Hirotani T, Kameda T, Kumamoto T, Shirota S. Results of total aortic arch replacement for an acute aortic arch dissection. J Thorac Cardiovasc Surg. 2000; 120:686-91

22. Bernard Y, Zimmermann H, Chocron S, Litzler JF, Kastler B, Etievent JP, et al. False lumen patency as a predictor of late outcome in aortic dissection. Am J Cardiol. 2001;87:1378-82.

23. Fattouch K, Sampognaro R, Navarra E, Caruso M, Pisano C, Coppola G, et al Long-term results after repair of type A acute aortic dissection according to false lumen patency. Ann Thorac Surg. 2009;88:1244-50.

24. David TE, Armstrong S, Ivanov J, Barnard S. Surgery for acute type A aortic dissection. Ann Thorac Surg. 1999;67:1999-2001. 